\title{
O Acesso à Justiça em Ponta Grossa-PR: \\ Um Olhar a Partir dos Relatórios da CIDH Sobre Acesso à Justiça no Brasil
}

\author{
Andressa Pacenko Malucelli \\ Graduação em Direito pela Universidade Estadual de Ponta Grossa (UEPG). Mestrado em Direito pela Pontifícia \\ Universidade Católica do Paraná (PUC/PR). Doutoranda em Ciências Sociais Aplicadas na UEPG. Professora na \\ Graduação do curso de Direito da Universidade Estadual de Ponta Grossa e supervisora do Projeto de Extensão \\ Núcleo Maria da Penha (Numape) e Projeto de Pesquisa O direito das famílias, os novos arranjos familiares da \\ pós-modernidade e seus reflexos na seara cível. http://lattes.cnpq.br/8868566295454338. \\ https://orcid.org/0000-0002-1006-0838. andressapacenko@hotmail.com
}

\section{Julia Maria Milanese Buffara}

Graduação em Direito e Especialização em Direito Processual Civil pela Universidade Estadual de Ponta Grossa. Mestrado em Direito Econômico e Social pela Pontifícia Universidade Católica do Paraná. Professora na Universidade Estadual de Ponta Grossa, com tempo integral e dedicação exclusiva. Supervisora no Projeto de Pesquisa Mecanismos de Efetivação dos Direitos Fundamentais. Supervisora no Projeto de Extensão Núcleo Maria da Penha (Numape) e Doutoranda no Programa de Pós-Graduação Interdisciplinar em Desenvolvimento Comunitário da Unicentro, PR. Tem experiência na área de Direito, com ênfase em Direito Público. http://lattes.cnpq.br/6754139486444339. https://orcid.org/0000-0003-3874-418X. milanesebuffara@gmail.com

\section{Dircéia Moreira}

Graduação em Direito pela Universidade Estadual de Ponta Grossa (UEPG). Mestrado em Direito das Relações Sociais e doutorado em Direito pela Pontifícia Universidade Católica de São Paulo (PUC/SP). Docente do Centro de Ensino Superior dos Campos Gerais e adjunta da Universidade Estadual de Ponta Grossa. Tem experiência na área de Direito, com ênfase em Direito Penal, atuando principalmente nos seguintes temas: adolescente egresso do sistema socioeducativo, políticas públicas, família e cidadania. http://lattes.cnpq.br/4448502240593013. https://orcid.org/0000-0001-6203-0246. dirceiam@uol.com.br

Nos Estados latino-americanos, marcados majoritariamente por profunda desigualdade social, o acesso à justiça reveste-se de especial importância, uma vez que é principalmente por meio dele que se busca a efetivação dos demais direitos humanos. Com este trabalho objetivou-se analisar os relatórios de mérito emanados da Comissão Interamericana de Direitos Humanos (CIDH), em que o Brasil foi parte, para evidenciar sob quais fundamentos há violação do acesso à justiça neste país. Partindo desta reflexão, correlacionaram-se os resultados de pesquisa feita pelo Núcleo de Pesquisa em Direitos Humanos, Estado e Políticas Públicas do Programa de Pós-Graduação em Ciências Sociais Aplicadas da Universidade Estadual de Ponta Grossa. A referida pesquisa desenvolveu-se de forma mista (quantitativa e qualitativa), de agosto a novembro de 2018, sendo um estudo de caso, pelo qual coletaram-se dados sobre ações, projetos ou programas existentes em Ponta Grossa-PR que proporcionam acesso à justiça à população local. Neste trabalho adotou-se o método dedutivo. Os procedimentos metodológicos foram pesquisa bibliográfica, documental e formulário de entrevista. Dos relatórios analisados, constatou-se que a violação do acesso à justiça, suscitada perante a $\mathrm{CIDH}$, refere-se primordialmente a homicídios consumados ou tentados, praticados majoritariamente por policiais, sob a predominância de dois fundamentos: morosidade de tramitação processual e falha na coleta de provas. No que se refere à pesquisa desenvolvida em Ponta Grossa, verificou-se inexistência de qualquer ação, projeto ou programa que vise a coibir as violações apuradas nos relatórios. Concluiu-se pela necessidade de criação de mecanismos eficazes para coibição dessas práticas, bem como superação de profundas desigualdades políticas e sociais.

Palavras-chave: Acesso à justiça. Violação. Relatórios de mérito. Comissão Interamericana de Direitos Humanos.

THE ACCESS TO JUSTICE IN PONTA GROSSA-PR:

AN INSIGHT BASED ON THE IACHR REPORTS ON THE ACCESS TO JUSTICE IN BRAZIL

In Latin-American countries, all greatly marked by social inequality, the access to justice is of substantial importance, due to the fact that it is the only mean to ensure an effective implementation of the Human Rights guidelines. This paper aims to analyze the merits reports issued by the Inter-American Commission on Human Rights (IACHR) in which Brazil was a part of, in order to point out the breaches in the process of access to justice in the aforementioned country. In view of this analysis, the research results from the Human Rights, State and Public Policies Research Center of the Ponta Grossa-PR State University Postgraduate Program in Applied Social Sciences were correlated. The research was developed both in quantitative and qualitative molds, from august to november 2018; it is a case study in which data on programs aimed to facilitate the access to justice by the locals in Ponta Grossa were 


\title{
Humanos e \\ Democracia
}

\begin{abstract}
collected and analyzed. This work was performed by the guidelines of a deductive approach. Interview forms, bibliographic and documental research were the methodological procedures to develop this paper. The analyzed data from the IACHR reports showed that the breaches in the access to justice mainly refer to manslaughter and assault with the attempt to commit murder performed mostly by police officers. In these situations, two aspects prevailed: slowness in the procedural steps and flaws in the process of evidence gathering. The research made in Ponta Grossa showed that there are no programs aimed to decrease the breaches found in the reports. In conclusion, the elaboration of effective means to decrease these breaches is extremely necessary, as it is to overcome any and all of the social and political inequality caused by those breaches.

Keywords: Access to justice. Breach. Merits reports. Inter-American Commission on Human Rights.
\end{abstract}

SUMÁRIO

1 Introdução. 2 Problema. 3 Metodologia. 4 Resultados e discussão. 5 Considerações finais. 6 Referências.

\section{INTRODUÇÃO}

O acesso à justiça é um direito humano fundamental, reconhecido ao longo do tempo em diversos tratados internacionais, como no artigo 18 da Declaração Americana dos Direitos e Deveres do Homem de 1948; no artigo 8o da Declaração Universal dos Direitos Humanos do mesmo ano, no artigo 20 do Pacto Internacional de Direitos Civis e Políticos de 1966, no artigo 8 da Convenção Americana de Direitos Humanos de 1969, entre outros. Muitos eventos contribuíram para se chegar a esse estado de reconhecimento, posto que na Europa, segundo Boaventura de Sousa Santos (1999, p. 146), a questão do acesso explodiu no pós-guerra, quando, após estudos sociológicos, se concluiu que obstáculos econômicos, sociais e culturais impediam o acesso efetivo da população à justiça.

Já na América Latina ${ }^{1}$ ele passou a ter relevância na década de 80 com a estabilização política e econômica ocorrida em muitos países. Como consequência desse evento, sobreveio a análise do sistema de justiça que à época vigorava e a discussão sobre os problemas que dificultavam o acesso à justiça da população. Esta análise, preconizada principalmente nos estudos de Boaventura de Sousa Santos (2011, p. 4), ficou explicitada em sua obra "Para uma revolução democrática da justiça" que foi fruto de uma palestra proferida no Brasil em 2007, com o tema "Democratização do acesso à justiça", que apontou necessária ampliação do acesso à justiça nos países integrantes da América Latina, tendo em vista a grande lentidão no tratamento dos processos, a dificuldade de acesso e, sobretudo, a baixa confiança da população no Judiciário.

Delimitados os problemas, com a participação de vários organismos internacionais, entre eles o Banco Mundial, reformas judiciais foram organizadas e restaram criadas na América Latina novas instituições que tinham por objetivo estender o acesso ao Poder Judiciário da

\footnotetext{
A ONU classifica os Grupos Regionais das Nações Unidas dos Estados Membros e inclui a América Latina no Grupo Latino-Americano e Caribenho (Grulac), que é formado pelos seguintes países: Antígua e Barbuda, Argentina, Bahamas, Barbados, Belize, Bolívia (Estado Plurinacional de), Brasil, Chile, Colômbia, Costa Rica, Cuba, Dominica, República Dominicana, Equador, El Salvador, Granada, Guatemala, Guiana, Haiti, Honduras, Jamaica, México, Nicarágua, Panamá, Paraguai, Peru, São Cristóvão e Névis, Santa Lúcia, São Vicente e Granadinas, Suriname, Trinidad e Tobago, Uruguai e Venezuela (República Bolivariana da). Disponível em: http://www.un.org/depts/DGACM/RegionalGroups.shtml. Acesso em: 26 jan. 2019.
} 
população economicamente desfavorecida, por meio de uma justiça baseada em princípios como celeridade, informalidade, oralidade, conciliação e gratuidade para os necessitados. Foram criados no Brasil, por exemplo, os Juizados de Pequenas Causas.

Em que pese novas diretrizes tenham sido adotadas e mudanças legislativas tenham sido instituídas para se proporcionar um efetivo acesso à justiça à população, muito há que ser feito ainda no Brasil, consoante ver-se-á adiante.

\section{PROBLEMA}

Nos estados latino-americanos, marcados, em sua maioria, por profunda desigualdade social, o acesso à justiça reveste-se de especial importância, uma vez que, por meio dele, tutelam-se todos os demais direitos. De acordo com Boaventura de Sousa Santos (1999, p. 146),

a consagração constitucional dos novos direitos econômicos e sociais e a sua expansão paralela à do Estado-Providência transformou o direito ao acesso efectivo à justiça num direito charneira, um direito cuja denegação acarretaria a de todos os demais.

Hannah Arendt (1989, p. 332), por sua vez, observa que o "direito fundamental de cada indivíduo, antes de qualquer direito enumerado em declarações, é o direito a ter direitos, isto é, o direito de pertencer a uma comunidade disposta e capaz de garantir-lhe qualquer direito."

Acesso à justiça, portanto, assegura a dignidade da pessoa humana, sendo expressão de Estado Democrático e condição fundamental para o exercício da cidadania. Diante disso, valendo-se de políticas públicas adequadas, um estado deve garanti-lo à sua população. Isso, no entanto, não significa proporcionar às pessoas a trivial assistência judiciária, ou o mero acesso ao Poder Judiciário por meio do exercício do direito de ação, mas, sim, um acesso inclusivo, efetivo, pleno e humanizado à ordem jurídica, justa e em todas as suas possíveis formas. Nestes termos, pode-se afirmar que o acesso à justiça é meio eficaz para a emancipação do homem.

No Brasil, o acesso à justiça, hoje, está previsto no artigo 50, inciso XXXV, da Constituição Federal de 1988. Observa-se, ainda, que todas as constituições brasileiras garantiram aos cidadãos a via judiciária, contudo, de acordo com o suprarreferido, é importante colacionar observação feita por Marlise Matos (2010/2011, p. 13-14) em trabalho vinculado ao Centro de Estudos Sociais América Latina (CES-AL), Observatório da Justiça Brasileira, que assim se manifesta:

Parece-nos, contudo, ilusória a simples garantia formal, abstrata e universal do acesso ao Judiciário, quando tantos são os obstáculos que se interpõem à efetiva reparação aos direitos violados no Brasil. Entende-se que tal garantia constitucional somente se aperfeiçoará se, além de não haver exclusão legal da apreciação judicial, isto é, se além da garantia formal de não ser excluído da apreciação do Judiciário qualquer lesão ou ameaça a direito, ocorrer a real reparação do direito violado, ou o impedimento que a ameaça ao direito se concretize. Isto é, que haja acesso à justiça e, posteriormente, seja conferida eficácia à decisão judicial. Cabe mencionar aqui uma precisão conceitual que nos é importante: a diferenciação entre "acesso à justiça" e "acesso ao sistema jurídico". Acessar o sistema jurídico refere-se exclusivamente a um tipo de acesso apenas formal, como ingressar com um processo etc. $O$ "acesso à justiça" como o estamos tratando aqui é mais 


\section{Humanos e \\ Democracia}

complexo e amplo do que tal dimensão formal e pode, inclusive, ser realizado por meios não jurídicos e diz não só do processo/procedimento, mas também daqueles que seriam (ou deveriam ser) os seus principais resultados.

$\mathrm{O}$ acesso à justiça enquanto direito humano, como anotado anteriormente, recebeu tutela internacional. Piovesan e Ikawa (2007, p. 309) observam que: "Desde o pós-guerra, os direitos humanos passam a constituir tema de legítimo interesse da comunidade internacional, em crescente processo de internacionalização." As mesmas autoras (2007, p. 309) ponderam que, na esfera global, existem vários tratados sobre a temática no âmbito na Organização das Nações Unidas - ONU -, em que Comitês instituídos pelos próprios tratados, enquanto órgãos políticos, e, por vezes quase-judiciais, monitoram o cumprimento dos direitos preconizados em ditos documentos.

De forma diversa do sistema global, os sistemas regionais de proteção aos direitos humanos têm revelado peculiares experiências na forma de operar a proteção destes direitos, criando Comissões e Cortes, como é o caso do Sistema Interamericano de Direitos Humanos.

Instituído pela Organização dos Estados Americanos (OEA) - fundada no ano de 1948, atualmente com 35países membros, dentre eles o Brasil -, o Sistema Interamericano de Direitos Humanos foi criado baseado em dois principais diplomas: a Carta da OEA e a Convenção Americana de Direitos Humanos (CADH). Calcada em tais documentos, em 1960 a OEA estabeleceu a Comissão Interamericana de Direitos Humanos (MINISTÉRIO..., 2010, p. 73).

A Comissão Interamericana, antes da entrada em vigor da $\mathrm{CADH}$, tinha como funções receber petições individuais contendo denúncias de violações de direitos, bem como realizar estudos e investigações nos Estados membros (MINISTÉRIO..., 2010, p. 73). Com a aprovação da CADH em 1969 - e vigência a partir de 1978 - são consagrados dois órgãos para a proteção dos direitos humanos: a Comissão e a Corte Interamericana de Direitos Humanos.

A Comissão, então, na promoção e defesa dos direitos humanos no continente americano, passa a dispor de vários instrumentos, podendo, por exemplo, apresentar aos governos dos Estados-Membros recomendações de medidas progressivas em prol dos direitos humanos, conduzir investigações presenciais em um Estado-Membro, preparar relatórios dos Estados e enviar missões de "observadores" (CONVENÇÃO..., 1969, artigo 41). Do mesmo modo, está habilitada a receber petições individuais, que podem ser encaminhadas até mesmo por pessoas que não sejam as vítimas da violação do direito suscitado (CONVENÇÃO..., 1969, artigo 44). Ainda, ela é destinatária de queixas facultativas dos Estados, para o que estes devem entregar uma declaração, adicionalmente à ratificação, com a qual reconheçam a competência da Comissão para procedimentos intergovernamentais (CONVENÇÃO..., 1969, artigo 45).

Por conseguinte, a violação de um direito proclamado na $\mathrm{CADH}$, ou em outro tratado internacional, é passível de ser denunciada perante a Comissão Interamericana, como é o caso da violação do direito de acesso à justiça.

Sendo o Brasil o maior país latino-americano, importa refletir até que ponto esse acesso é garantido à sua população e até onde isso resulta em efetividade ou utilização concreta dos direitos previstos em abstrato no seu ordenamento jurídico. 
Para realizar essa reflexão, propõe-se, por intermédio do presente, uma análise dos relatórios de mérito emanados da Comissão Interamericana de Direitos Humanos - CIDH -, por meio dos quais verificar-se-á a forma como este direito tem sido reiteradamente violado pelo Estado brasileiro, para, em seguida, analisar se, ao menos localmente, há alguma ação, programa ou projeto sendo desenvolvido na tentativa de evitar essas violações. Isso será feito com base em pesquisa quanti-qualitativa realizada no período de agosto a novembro de 2018 pelos membros do Núcleo de Pesquisa em Direitos Humanos, Estado e Políticas Públicas do Programa de Pós-Graduação em Ciências Sociais Aplicadas (PPGCSA) da Universidade Estadual de Ponta Grossa - UEPG -, Paraná/Brasil, uma importante cidade universitária, com população atual estimada em cerca de 348.000 habitantes (IBGE, 2018).

\section{METODOLOGIA}

O presente estudo, no que se refere aos procedimentos metodológicos, sustenta-se na pesquisa bibliográfica e documental, esta última voltada à análise dos relatórios de mérito emanados da Comissão Interamericana de Direitos Humanos, em que o Estado brasileiro foi parte. Utilizou-se, ainda, um formulário estruturado para coleta de informações sobre as experiências locais relativas ao acesso à justiça que contemplou: identificação do equipamento, programa, projeto ou ação; objetivos; estrutura; composição da equipe; atribuições da equipe; demandas/usuários; articulação entre políticas e relação com direitos humanos.

O formulário supramencionado faz parte de uma pesquisa do Núcleo de Direitos Humanos, Estado e Políticas Públicas do Programa de Pós-Graduação em Ciências Sociais Aplicadas da UEPG, e possui natureza mista, ou seja, articula a dimensão qualitativa e quantitativa, buscando apresentar dados que caracterizam o universo pesquisado, especialmente quanto à população atendida e equipes de referência, e a compreensão dos sujeitos pesquisados referentes à relação entre política pública e direitos humanos. No contexto da abordagem quali-quantitativa, a pesquisa classifica-se como um estudo de caso.

O estudo de caso permite que se reconheçam os modos de atuação, funcionamento e resultados das políticas adotadas pelas organizações na cidade em que se realizou a pesquisa, abordados por meio de perspectivas dos sujeitos envolvidos. Sobre tal abrangência, destaca-se o que afirma Quimelli (2009, p. 73):

Os Estudos de Caso podem especialmente ser utilizados quando o objetivo do pesquisador não é simplesmente ver o que os sujeitos de pesquisa entendem sobre determinado assunto, mas o que e como eles trabalham na prática o tema a ser investigado, e como este tema influencia criticamente as suas vivências diárias.

No caso do acesso à justiça, o universo pesquisado consistiu-se no: Fórum da Justiça Estadual; Fórum da Justiça Federal e do Trabalho; Ministério Público Federal, Estadual e do Trabalho; Defensoria Pública; Centro Judiciário de Soluções de Conflitos - Cejusc -; Polícias Civil, Militar e Federal; Prefeitura Municipal; Ordem dos Advogados do Brasil; Universidades e Faculdades, todos eles em âmbito local. A partir da delimitação do referido universo, iniciou-se a coleta de informações. 


\section{Democracia}

Foi constatada a existência de 20 projetos/programas/ações, dos quais 1 é programa, 15 são projetos e 4 são Núcleos de Práticas Jurídicas ligados às Instituições de Ensino Superior existentes na cidade. Os coordenadores ou responsáveis foram entrevistados, e o principal foco de atuação deles será a seguir descrito.

Os resultados estão expostos correlacionando a ligação entre os serviços ofertados e as principais formas de violação de acesso à justiça apontadas nos relatórios de mérito da Comissão Interamericana de Direitos Humanos.

\section{RESULTADOS E DISCUSSÃO}

Inicialmente é relevante consignar que a CADH foi assinada e ratificada pelo Brasil em setembro de 1992.

Neste sentido observa-se, conforme ensina Piovesan (2010, p. 165), que a simples assinatura de um tratado não irradia efeitos jurídicos vinculantes e "trata-se de mera aquiescência do Estado com relação à forma e conteúdo final do tratado," indicando apenas que "o tratado é autêntico e definitivo". A autora explica que, após a assinatura do tratado pelo Poder Executivo, o mesmo é submetido ao Poder Legislativo para apreciação, posto que, após aprovado, deverá ser ratificado pelo Poder Executivo.

Para Francisco Rezek (2014, p. 74), ratificação "é o ato unilateral com que a pessoa jurídica de direito internacional, signatária de um tratado, exprime definitivamente, no plano internacional, sua vontade de obrigar-se".

Após ratificado, o instrumento deve ser depositado em um órgão que assuma sua custódia, o que, no caso da CADH, deverá ser feito na Secretaria Geral da Organização dos Estados Americanos (CONVENÇÃO..., 1969, artigo 74.2).

Ainda, segundo Piovesan (2010, p. 169), os tratados de direitos humanos possuem aplicação imediata no ordenamento jurídico brasileiro, de forma que, assim que ratificados, "irradiam efeitos no cenário internacional e interno, dispensando-se a edição de decreto de execução".

No que se refere à incorporação dos tratados ao ordenamento jurídico brasileiro, o parágrafo terceiro do artigo 50 da Constituição Federal (BRASIL, 1988) - incluído pela Emenda Constitucional no 45 de 2004 - dispõe que:

Os tratados e convenções internacionais sobre direitos humanos que forem aprovados, em cada Casa do Congresso Nacional, em dois turnos, por três quintos dos votos dos respectivos membros, serão equivalentes às emendas constitucionais.

Até agora, contudo, não houve referida votação no que diz respeito à CADH no Congresso Brasileiro.

Inobstante o status de sua recepção no ordenamento jurídico brasileiro, tendo sido ratificado, e tendo o Estado brasileiro submetido-se à jurisdição da Comissão e Corte Interamericanas, está sujeito a processamento se houver violação dos direitos humanos, como ocorreu em vários casos em que ocorreu ofensa ao direito de acesso à justiça. 
Registra-se, ainda, antes da descrição dos casos de violação apurados, que, para que uma situação possa ser submetida à análise da Comissão por meio de petições individuais, é preciso observar o seguinte:

Artigo 46. 1. Para que uma petição ou comunicação apresentada de acordo com os artigos 44 ou 45 seja admitida pela Comissão, será necessário:

a. que hajam sido interpostos e esgotados os recursos da jurisdição interna, de acordo com os princípios de direito internacional geralmente reconhecidos;

b. que seja apresentada dentro do prazo de seis meses, a partir da data em que o presumido prejudicado em seus direitos tenha sido notificado da decisão definitiva;

c. que a matéria da petição ou comunicação não esteja pendente de outro processo de solução internacional; e

d. que, no caso do artigo 44, a petição contenha o nome, a nacionalidade, a profissão, o domicílio e a assinatura da pessoa ou pessoas ou do representante legal da entidade que submeter a petição (CONVENÇÃO..., 1969).

Da mesma forma, o artigo 47 da Convenção dispõe que será considerada inadmissível a petição nos casos em que:

a. não preencher algum dos requisitos estabelecidos no artigo 46;

b. não expuser fatos que caracterizem violação dos direitos garantidos por esta Convenção;

c. pela exposição do próprio peticionário ou do Estado, for manifestamente infundada a petição ou comunicação ou for evidente sua total improcedência; ou

d. for substancialmente reprodução de petição ou comunicação anterior, já examinada pela Comissão ou por outro organismo internacional (CONVENÇÃO..., 1969).

Uma vez reconhecida a admissibilidade da petição, a Comissão solicitará informações ao Estado denunciado, a fim de garantir o contraditório. Ato contínuo, é verificada a existência ou não dos motivos que levaram ao peticionamento, posto que, em caso negativo, o expediente será arquivado, e, em caso positivo, será realizado um exame acurado do assunto e investigação dos fatos, se necessário (CONVENÇÃO..., 1969, artigo 48).

Examinados os fatos, a Comissão proporá uma solução amigável entre o Estado e o denunciante, a qual, sendo aceita, será transmitida ao peticionário e aos Estados-partes, e, após, elaborado informe contendo exposição dos fatos e a solução encontrada para resolução, com a respectiva comunicação à Secretaria da Organização dos Estados Americanos para publicação (CONVENÇÃO..., 1969, artigo 49).

Em caso de não aceitação da proposta, é emitido um relatório pela Comissão Interamericana de Direitos Humanos, com apresentação dos fatos e conclusões pertinentes a violação submetida à apreciação, inclusive com indicação se o Estado violou ou não a Convenção Americana. O referido relatório na sequência é encaminhado ao Estado-parte com recomendações da Comissão, as quais deverão ser cumpridas no prazo de três meses. Durante este prazo, o caso pode ser solucionado pelas partes, encaminhado à Corte Interamericana de Direitos Humanos, ou, ainda, não ser solucionado. Nesta última hipótese, tendo o Estado reconhecido a competência da Comissão, esta poderá emitir, por voto da maioria absoluta de seus 


\section{Democracia}

membros, sua conclusão, estabelecendo recomendações pertinentes e fixando um prazo para cumprimento. Finalmente, se houver o não cumprimento das recomendações pelo Estado envolvido, a Comissão decidirá, também por voto da maioria absoluta de seus membros, se publica o Relatório (CONVENÇÃO..., 1969, artigo50-51).

Por meio do presente estudo, realizou-se a análise de todos os Relatórios de mérito emanados da $\mathrm{CIDH}$ dos casos que envolveram denúncias contra o Estado brasileiro, desde que este aceitou sua competência, o que se deu no ano de 1998. Assim, foram considerados 25 casos, identificados sob os seguintes números: 12.213; 12.308; 12.440; 12.310; $12.019 ; 12.001 ; 11.556 ; 11.634 ; 10.301 ; 11.517 ; 12.051 ; 11.286 ; 11.407 ; 11.406 ; 11.416$; 11.413; 11.417; 11.412; 11.415; 11.291; 11.598; 11.599; 11.405; 11.516; e 11.287 (CIDH, 2018)

Analisando-se os relatórios, verificou-se que na totalidade dos casos examinados houve violação do direito de acesso à justiça. Os casos que envolveram a referida violação traduzem-se em:

\section{Gráfico 1 - Denúncias submetidas à Comissão Interamericana contra o Estado brasileiro}

\section{DENÚNCIAS SUBMETIDAS À COMISSÃO INTERAMERICANA CONTRA O ESTADO BRASILEIRO \\ - HOMICÍDIO / TENTATIVA DE HOMICÍDIO PRATICADO POR CIVIL \\ - HOMICÍDIO / TENTATIVA DE HOMICÍDIO PRATICADO POR POLICIAL \\ = DETENÇÃ̃O ILEGAL / TORTURA \\ = DISCRIMINAÇ̃̃O RACIAL}

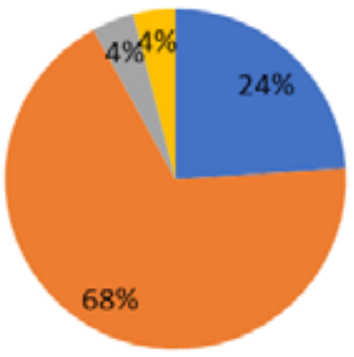

Fonte: CIDH (2018). Dados sistematizados pelas autoras.

É relevante ainda observar sob quais fundamentos a Comissão entendeu haver violação do direito de acesso à justiça: 
Gráfico 2 - Fundamentos da violação do direito de acesso à justiça

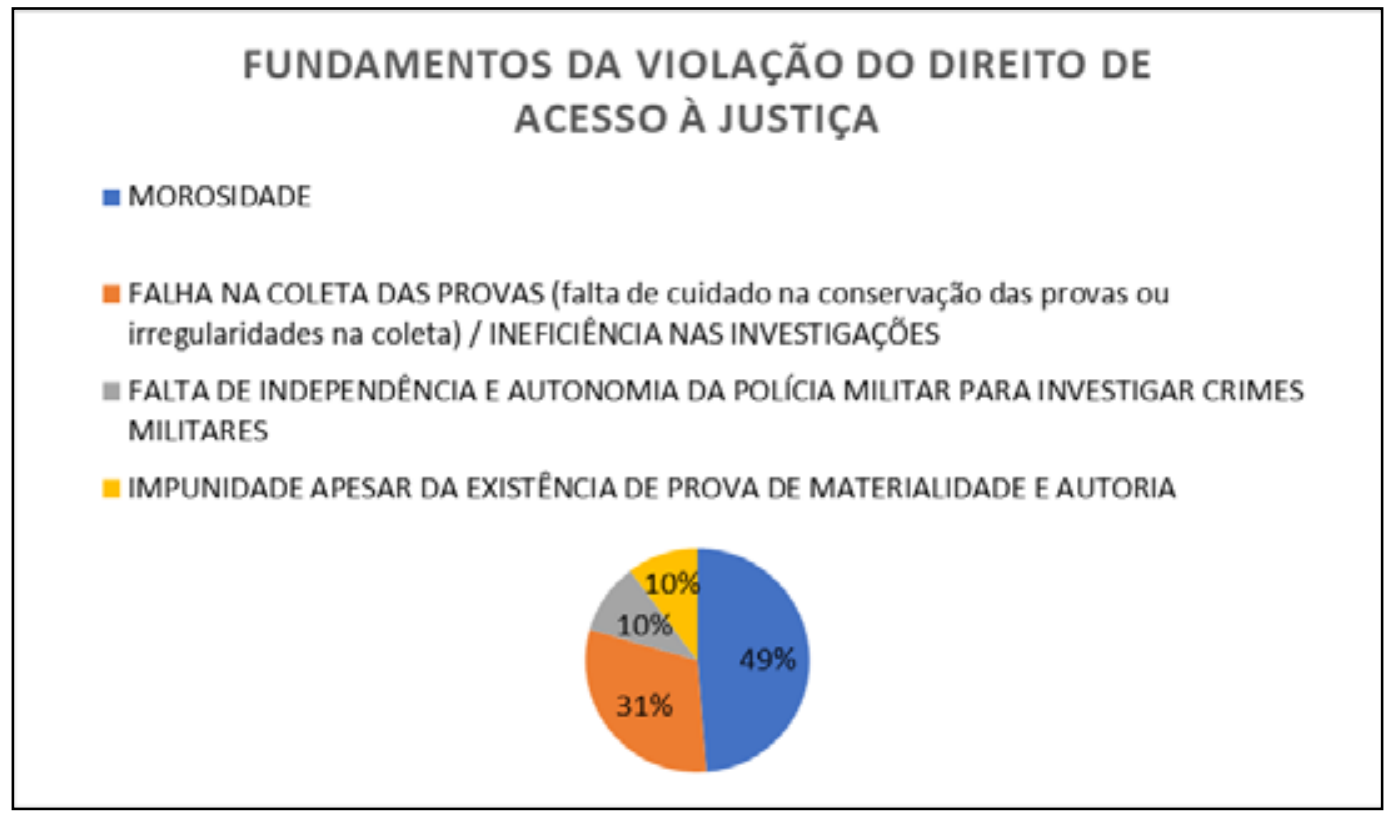

Fonte: CIDH (2018). Dados sistematizados pelas autoras.

É de extrema relevância esclarecer que em cada um dos casos analisados a violação do direito de acesso à justiça pode ter possuído mais de um fundamento.

Conforme denota-se dos gráficos supra, a problemática da violação do acesso à justiça suscitada perante a CIDH concentra-se primordialmente na esfera criminal, em razão de homicídios consumados ou tentados, praticados majoritariamente por policiais, em que se observa, em grande parte, flagrante morosidade de tramitação processual, o que, por vezes, resultou, inclusive, em prescrição da pretensão punitiva.

Neste viés, é importante observar que a morosidade na tramitação do processo gera violação tanto no direito de acesso à justiça da vítima, na medida em que para esta o acesso à justiça pode ser compreendido como ver aplicada a punição ao(s) seu(s) ofensor(es), quanto para seus familiares, uma vez que o eventual pedido de indenização em razão do crime perpetrado fica subordinado à procedência da ação penal, conforme observado no relatório do caso 12.440 .

Outro fator de relevante expressão foram as falhas na coleta de provas, traduzidas, por vezes, em falta de cuidado em sua conservação, ou irregularidades na sua coleta, bem como ineficiência nas investigações. Aliado a isto, há que se sopesar duras críticas feitas pela Comissão com relação à falta de independência e autonomia da justiça militar para conduzir investigações de crimes militares, o que comprometeu, em alguns casos de forma irremediável, os julgamentos. Finalmente, apontaram-se em alguns casos a impunidade pura e simples, em que pese tenham sido colhidas provas que demonstravam autoria e materialidade dos delitos.

Segundo recente estudo publicado no Human Rights Watch, no Brasil "Abusos cometidos pela polícia, incluindo execuções extrajudiciais, contribuem para um ciclo de violência que prejudica a segurança pública e coloca em risco a vida de policiais e civis" (HUMAN RIGHTS WATCH, 2019). Na mesma matéria noticia-se que o Brasil não cumpriu determinação da Corte 


\section{Humanos e \\ Democracia}

Interamericana de Direitos Humanos de 2017, pela qual ficara obrigado a publicar relatório anual sobre letalidade policial e mortes de policiais. O Fórum Brasileiro de Segurança Pública, organização não governamental, compilou dados de fontes oficiais que demonstram que policiais, em serviço ou não, mataram 5.144 pessoas em 2017, o que representa um acréscimo de $20 \%$ em relação ao ano anterior. Não obstante, um ouvidor da polícia do Estado de São Paulo procedeu, em 2017, análise de centenas de homicídios praticados por policiais, concluindo que houve excessivo uso de força em três a cada quatro casos, por vezes praticados contra pessoas desarmadas.

Keymer Ávila (2018), em artigo eletrônico, reportou-se a um comunicado da Associação Latino-Americana de Direito Penal e Criminológico, por meio do qual esta externalizou preocupação com o comportamento dos sistemas criminais nos países latino-americanos, em que não são observados quaisquer limites legais ou institucionais, e as milhares de mortes que as forças de segurança geraram nos últimos anos. No mesmo trabalho, o autor divulga resultado de uma pesquisa feita por Ignacio Cano e Anneke Osse, em que se analisou a taxa de "letalidade policial", figurando o Brasil entre os países com maior índice neste cenário, ao lado de Venezuela, Jamaica e El Salvador.

Da análise dos julgados da CIDH, aliada aos recentes dados mencionados supra, percebe-se que o Brasil é, ainda, um Estado deficitário no que diz respeito ao dever de garantir o direito humano fundamental de acesso à justiça inclusivo, efetivo, pleno e humanizado. Isso constata-se pela ocorrência de fatos que prejudicam investigações eficientes e independentes, pelos arquivamentos imotivados de inquéritos policiais, pela morosidade em prestar a tutela jurisdicional devida, enfim, pela impunidade resultante desses fatos e pela inércia do Estado em coibir essa violência do sistema contra os cidadãos.

Segundo Boaventura de Sousa Santos (2011, p. 6),

Somos herdeiros das promessas da modernidade e, muito embora as promessas tenham sido auspiciosas e grandiloquentes (igualdade, liberdade, fraternidade), temos acumulado um espólio de dívidas. [..] Se as promessas da modernidade continham em si um vigoroso potencial emancipatório, o afunilamento desse projeto político-cultural, a par do avanço e da consolidação do capitalismo como modo de produção, transformou a emancipação e a regulação social em duas faces da mesma moeda.

Embora no Brasil, como resultado dos esforços despendidos na década de 80 do século 20 para ampliar o acesso à justiça, consubstanciados no artigo 5, LXXIV e 134 da Constituição Federal de 1988, estejam presentes, ainda, as Assessorias Jurídicas Universitárias, o Programa Justiça Comunitária, a Advocacia Popular e os Juizados Especiais, ou seja, instituições capazes de contribuir com o Estado na tarefa de garantir acesso à justiça, é imperioso reconhecer que, assim como em toda a América Latina, o potencial do direito para ser emancipatório pressupõe, no pensar de Boaventura de Sousa Santos (2011, p. 24), a necessidade de uma "revolução democrática da justiça" que leve em conta a diversidade jurídica existente no mundo para formar o pensamento jurídico crítico. Para tanto, o autor aponta como sendo os principais vetores dessa transformação:

profundas reformas processuais; novos mecanismos e novos protagonismos no acesso ao direito e à justiça; o velho e o novo pluralismo jurídico; nova organização e gestão judiciárias; revolução na formação profissional, desde as faculdades de direito até a formação 
permanente; novas concepções de independência judicial; uma relação do poder judicial mais transparente com o poder político e a mídia, e mais densa com os movimentos e organizações sociais; Uma cultura jurídica democrática e não corporativa (2011, p. 25).

Além do que se observa nos julgados da CIDH, a concepção de Santos (2011) reputa-se verdadeira pelos resultados obtidos na pesquisa suprarreferida, realizada pelos membros do Núcleo de Pesquisa em Direitos Humanos, Estado e Políticas Públicas do Programa de Pós-Graduação em Ciências Sociais Aplicadas (PPGCSA) da UEPG, a qual buscou verificar os programas, projetos, serviços e ações de promoção dos direitos humanos nas políticas de assistência social, de acesso à justiça e de educação na cidade, e resultou, quanto ao acesso à justiça, o seguinte: vinculados ao Tribunal de Justiça do Estado do Paraná, à Universidade Estadual de Ponta Grossa, à Faculdade Educacional de Ponta Grossa, ao Centro de Ensino Superior dos Campos Gerais, às Faculdades Secal e à Vara da Infância e Juventude, foram encontradas 20 ocorrências, das quais 1 é programa, 15 são projetos e 4 são Núcleos de Práticas Jurídicas ligados às instituições de ensino superior existentes na cidade. Concluiu-se que, por meio deles, privilegiam-se o acesso à justiça da população com relativa efetividade em questões familiares, infância e juventude, violência contra a mulher, violência doméstica, descriminações de gênero e raça, justiça restaurativa e crimes de menor potencial ofensivo. Nenhum deles, todavia, volta-se a tentar coibir os abusos que foram apurados nos relatórios da $\mathrm{CIDH}$, objetos deste trabalho. Nenhum programa, projeto ou ação destina-se a fiscalizar e assegurar a independência da justiça militar, a acompanhar a produção e garantir a integridade de provas em ações penais, bem como não há esforços suficientes que evitem o problema da morosidade do Poder Judiciário, ainda que a razoável duração do processo seja garantia constitucional (artigo 5o LXXVIII CF).

\section{CONSIDERAÇÕES FINAIS}

Como resultado deste estudo, conclui-se que ainda resta muito a ser feito para se chegar à revolução democrática da justiça que Boaventura de Sousa Santos apregoa e defende em seus aprofundados estudos sociais.

A partir da década de 80, com a estabilização política e econômica e por influência dos referidos estudos realizados na América Latina, muito embora novas diretrizes tenham sido adotadas e mudanças legislativas instituídas para proporcionar o acesso à justiça à população do Brasil, muito ainda há que ser feito para que ele se traduza em acesso inclusivo, efetivo, pleno e humanizado à ordem jurídica justa. Não se nega a existência de progresso desde a redemocratização, contudo, não o suficiente para classificar o país, hoje, como essencialmente democrático. Para tanto, a despeito das solenes declarações em que os direitos humanos são reconhecidos, faz-se necessária a criação de mecanismos eficazes que impeçam sua violação em relação a todos os cidadãos, o que somente será possível quando as profundas desigualdades sociais e políticas ainda existentes forem superadas. A revolução democrática da justiça, que se espera tenha o potencial emancipatório no Brasil, depende, sobretudo, da existência de uma cidadania inclusiva. 


\section{Humanos e \\ Democracia}

\section{REFERÊNCIAS}

ARENDT, H. Origens do totalitarismo: antissemitismo, imperialismo, totalitarismo. Tradução Roberto Raposo. São Paulo: Companhia das Letras, 1989.

ÁVILA, K. Marielle y las muertes institucionales en América Latina, 2018. Disponível em: https://www.derechos. org.ve/opinion/marielle-y-las-muertes-institucionales-en-america-latina. Acesso em: 30 jan. 2019.

BRASIL. Constituição [da] República Federativa do Brasil. Brasília, DF: Senado, 1988. Disponível em: http://www. planalto.gov.br/ccivil_03/Constituicao/Constituicao.htm. Acesso em: 30 jan. 2019.

BRASIL. Lei no 1.060, de 5 de fevereiro de 1950. Diário Oficial [da] República Federativa do Brasil, Brasília, DF, 13 fev. 1950. Disponível em: http://www.planalto.gov.br/ccivil_03/leis/L1060compilada.htm. Acesso em: 30 jan. 2019.

BRASIL. Lei no 13.105, de 16 de março de 2015. Código de Processo Civil. Diário Oficial da União, Brasília, DF, 17 mar. 2015. Disponível em: http://www.planalto.gov.br/ccivil_03/_Ato2015-2018/2015/Lei/L13105.htm\#art1045. Acesso em: 30 jan. 2019.

$\mathrm{CIDH}$. Comisión Interamericana de Derechos Humanos. Disponível em: http://www.oas.org/es/cidh/decisiones/ fondos.asp. Acesso em: 30 nov. 2018.

CONVENÇÃO AMERICANA SOBRE DIREITOS HUMANOS. 1969. Disponível em: https://www.cidh.oas.org/basicos/ portugues/c.convencao_americana.htm. Acesso em: 14 dez. 2018.

DECLARAÇÃO AMERICANA DOS DIREITOS E DEVERES DO HOMEM. 1948. Disponível em: https://www.cidh.oas. org/basicos/portugues/b.Declaracao_Americana.htm. Acesso em: 14 dez. 2018.

DECLARAÇÃO UNIVERSAL DOS DIREITOS HUMANOS. 1948. Disponível em: https://www.ohchr.org/EN/UDHR/ Documents/UDHR_Translations/por.pdf. Acesso em: 14 dez. 2018.

HUMAN RIGHTS WATCH. Segurança pública e conduta policial. Disponível em: https://www.hrw.org/pt/world-report/2019/country-chapters/326447\#5d8cdf. Acesso em: 30 jan. 2019.

IBGE. Instituto Brasileiro de Geografia e Estatística. Disponível em: https://cidades.ibge.gov.br/brasil/pr/ponta-grossa/panorama. Acesso em: 16 dez. 2018.

MATOS, M. Acesso ao direito e à justiça brasileiros na perspectiva de gênero/sexualidade, raça/etnia: entre o Estado e a comunidade. Belo Horizonte: Faculdade de Filosofia e Ciências Humanas, 2010/2011.

MINISTÉRIO PÚBLICO DA UNIÃO. Manual prático de direitos humanos internacionais. Brasília: Escola Superior do Ministério Público da União, 2010. Disponível em: https://www.ufrgs.br/cedop/wp-content/uploads/2014/04/ Manual_Pratico_Direitos_Humanos_Internacioais-1.pdf. Acesso em: $18 \mathrm{dez} .2018$.

PACTO INTERNACIONAL SOBRE DIREITOS CIVIS E POLÍTICOS. 1966. Disponível em: http://www.planalto.gov.br/ ccivil_03/decreto/1990-1994/d0592.htm. Acesso em: 14 dez. 2018.

PIOVESAN, F.; IKAWA, D. (coord.). Direitos humanos: fundamento, proteção e implementação - perspectivas e desafios contemporâneos. Curitiba: Juruá, 2007.

PIOVESAN, F. Direitos humanos e o Direito Constitucional Internacional. 11. ed. São Paulo: Saraiva, 2010.

QUIMELLI, G. A. S. Considerações sobre o estudo de caso na pesquisa qualitativa. In: BOURGUIGNON, J. A. (org.). Pesquisa social: reflexões teóricas e metodológicas. Ponta Grossa: Toda Palavra, 2009.

REZEK, F. Direito Internacional Público: curso elementar. 15. ed. São Paulo: Saraiva, 2014.

SANTOS, B. S. Pela mão de Alice: o social e o político na pós-modernidade. São Paulo: Cortez, 1999.

SANTOS, B. S. Para uma revolução democrática da justiça. 3. ed. São Paulo: Cortez, 2011.

UNITED NATIONS UN. Disponível em: http://www.un.org/depts/DGACM/RegionalGroups.shtml. Acesso em: 25 jan. 2019. 